\title{
New Greener Method for the Preparation of Heteropolyacid Compounds (HPW) Modified with Metallic Tin and Application in the Lactic Acid Esterification Reaction
}

\author{
Mariane M. Henz, ${ }^{a}$ Munique G. Guimarães, ${ }^{a}$ Rafael B. W. Evaristo, ${ }^{a}$ Rafael O. Rocha, ${ }^{b}$ \\ Lennine R. de Melo, ${ }^{c}$ Julio L. de Macedo ${ }^{a, c}$ and Grace F. Ghesti ${ }^{\odot *, a}$ \\ ${ }^{a}$ Laboratório de Bioprocessos Cervejeiros e Catálise para Energias Renováveis (LaBCERva), \\ Instituto de Química, Universidade de Brasília, 70910-900 Brasília-DF, Brazil \\ ${ }^{b}$ Laboratório de Isolamento e Transformação de Moléculas Orgânicas (LITMO), \\ Instituto de Química, Universidade de Brasília, 70910-900 Brasília-DF, Brazil \\ ${ }^{c}$ Grupo de Novos Materiais para Catálise Química Sustentável (GNM), \\ Instituto de Química, Universidade de Brasília, 70910-900 Brasília-DF, Brazil
}

\begin{abstract}
The main objective of this work was to design an innovative method to prepare heterogeneous heteropolyacid catalysts. The heteropolyacid $\mathrm{H}_{3} \mathrm{PW}_{12} \mathrm{O}_{40}(\mathrm{HPW})$ was modified with tin(II) by two methodologies: a conventional aqueous ion-exchange (CS) and a redox solid-state (SS). In both cases, Fourier transform infrared spectroscopy (FTIR) and X-ray diffraction (XRD) measurements evidenced that Keggin structure was preserved. All materials were active in the esterification of lactic acid with several alcohols and a mechanism was proposed. The best results were obtained for octanol and benzyl alcohol, where higher conversion values were obtained. The catalytic activity (turnover frequency, TON) showed an efficient performance for the materials prepared with $4 \mathrm{~h}$ of calcination (CS4h and SS4h). However, the catalyst prepared by the SS method was in accordance with the development of environmentally friendly processes.
\end{abstract}

Keywords: heteropolyacid, tin(II), heterogeneous catalysis, esterification

\section{Introduction}

The sustainable industrial development has been attracting attention during the last decades. For this reason, green chemistry principles have been extensively reported in literature, such as, use of renewable feedstocks and heterogeneous catalysis processes. ${ }^{1}$ Heteropolyacids (HPAs) are massively used as homogeneous catalysts in acid or oxidative reactions due to their physicochemical properties, associated with high solubility in polar solvents. Thus, its immobilization in inorganic matrices or replacement of compensation protons by large cations, forming heteropolysalts, are alternatives for improving catalytic performance. ${ }^{1}$

A possible alternative to replace the use of traditional homogeneous catalysts is the development of efficient heterogeneous catalysts, which are less aggressive to the environment and active in esterification, polymerization and redox reactions. ${ }^{2}$ Moreover, studies related to catalyst

*e-mail: grace@unb.br synthetic methodologies can also be carried out to adapt processes to become environmentally friendly. These heterogeneous catalysts present appropriate physicochemical properties that allow their use in various reactions on an industrial scale. Some advantages can be pointed: stability in reaction media; mechanical separation of the reaction; high selectivity; reaction cycles without activity loss; and low corrosivity, when compared to homogenous acids. ${ }^{3}$

The esterification of lactic acid was carried out with the main purpose of evaluating the activity of the developed catalysts. Lactate esters are widely used as emulsifying agents, in the production of biodegradable polymers, and as solvents. They are also an alternative for the purification of lactic acid due to their higher volatility. ${ }^{4}$ Nowadays, there is a growing interest in biomass use for the production of chemical reagents, fuels and materials to replace fossil origin raw materials. ${ }^{5}$ Lactic acid is a promising feedstock since it can be produced from biomass (mainly carbohydrates and glycerol). In addition, lactate esters can also follow this sustainable pathway and be used as green solvents because of their biodegradable properties. 
Lactic acid is one of the most versatile chemical compounds, not only being used in the food industry, as a preservative, acidifying, and flavoring component, but also in textile, pharmaceutical, and chemical industries, as raw material for the production of lactate, propylene glycol, 2,3-pentanedione esters, propanoic acid, acrylic acid, acetaldehyde, among others. ${ }^{6}$ The lactic acid importance results from its usefulness as reagent for biodegradable solvents and polymers, in which the hydroxyl and carboxyl functional groups make it possible to participate in a wide variety of chemical reactions, as shown in Scheme 1. It has a high occurrence in nature and can be produced in huge quantities through low-cost fermentation process. ${ }^{6-8}$

Recently, the consumption of lactic acid has increased considerably due to the production of biodegradable and biocompatible polymers, such as poly(lactic acid) or PLA. ${ }^{8-10}$ Recent studies ${ }^{11}$ of bioabsorbable polyesters originated from lactic acid have excelled in the medical field. Bioabsorbable polymers are those capable of depolymerize completely in an aqueous environment in the corresponding monomers or in products that undergo metabolic action from living organisms.

The difference between lactic acid production capacity and its demand can be explained through sustainability problems associated to the waste generated by the synthetic fermentation route in industrial scale. It is important to emphasize that esters formed from lactic acid, besides having diverse uses, are also intermediaries in the process of purifying lactic acid by an alternative biotechnological production from residues, such as glycerol. Thus, Scheme 2 summarizes the present study goal, which is the lactic acid purification through esterification reaction using several alcohols with heterogeneous catalysis.

The esterification reaction with lactic acid described in this study was carried out using the following alcohols: methanol, ethanol, octanol, benzyl alcohol and tert-butyl

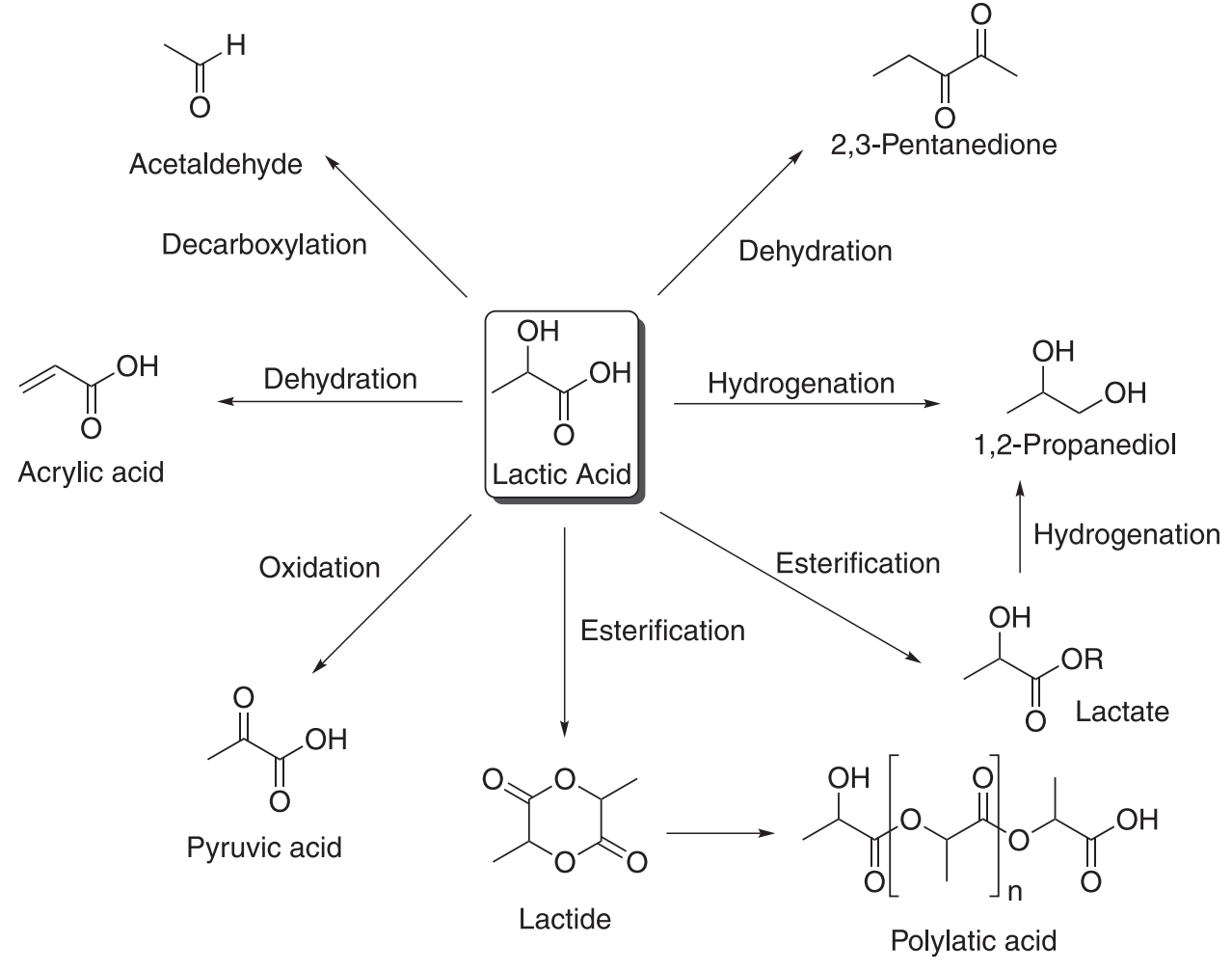

Scheme 1. Some lactic acid derivatives (adapted from Pereira et al. ${ }^{6}$ ).

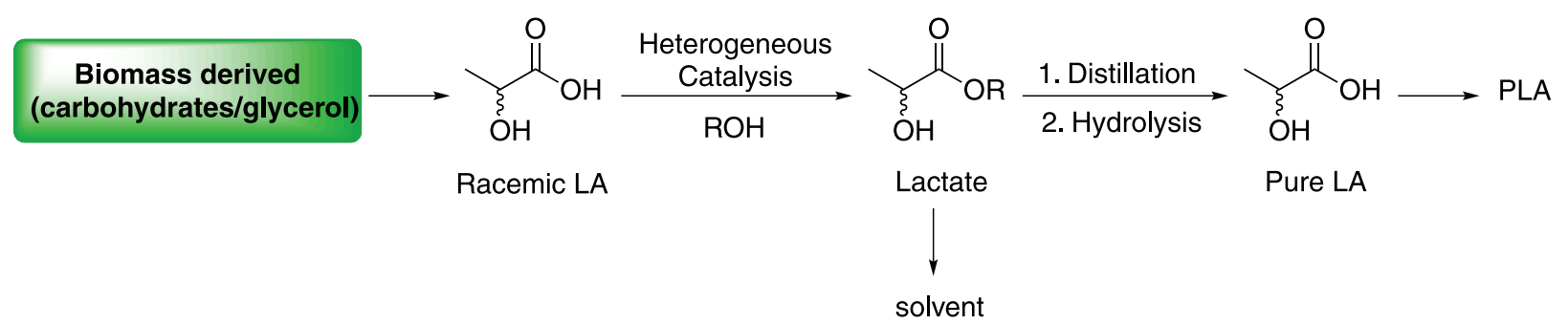

Scheme 2. Role of heterogeneous catalysis in the esterification reaction of lactic acid. ${ }^{8}$ 
alcohol. Methyl and ethyl lactates already have a wide range of studies ${ }^{6}$ and are industrially produced. For comparison, a long chain alcohol (octanol) was also studied since octyl esters have interest as cosmetics, fuels, polymers and others, ${ }^{12,13}$ expanding those applications to ester additives in biofuels. ${ }^{14}$

This work aim was to synthesize tin(II) modified heteropolyacid compounds and to study their structural and acidic properties. The materials were prepared by two methods: $(i)$ a conventional ion exchange procedure in aqueous solution; and (ii) a new redox solid-state process developed in our research group. Furthermore, the esterification of lactic acid with several alcohols was used to evaluate the tin(II) modified heteropolyacid catalytic activity.

\section{Experimental}

\section{Materials}

The materials 12-tungstophosphoric acid hydrate $\left(\mathrm{H}_{3} \mathrm{PW}_{12} \mathrm{O}_{40} \cdot \mathrm{nH}_{2} \mathrm{O}, \geq 95 \%\right.$, Sigma-Aldrich, Saint Louis, USA), tin(II) chloride dihydrate $\left(\mathrm{SnCl}_{2} \cdot 2 \mathrm{H}_{2} \mathrm{O}, \geq 99 \%\right.$, Merck, Darmstadt, Germany), tin (Sn, $\geq 99 \%$, SigmaAldrich, Saint Louis, USA), lactic acid $\left(\mathrm{C}_{3} \mathrm{H}_{6} \mathrm{O}_{3}\right.$, 84.5-85.5\%, Vetec, Rio de Janeiro, Brazil), tert-butanol $\left(\left(\mathrm{CH}_{3}\right)_{3} \mathrm{COH}, \geq 99 \%\right.$, Vetec, Rio de Janeiro, Brazil), octanol $\left(\left(\mathrm{CH}_{3}\right)_{7} \mathrm{CH}_{2} \mathrm{OH}, \geq 97 \%\right.$, Vetec, Rio de Janeiro, Brazil), benzyl alcohol $\left(\mathrm{C}_{7} \mathrm{H}_{8} \mathrm{O},>99 \%\right.$, Tedia, Fairfield, USA) and potassium bromide (KBr, $\geq 99.5 \%$, Merck, Darmstadt, Germany) were used as purchased. Methanol $\left(\mathrm{CH}_{3} \mathrm{OH}, \geq 99.8 \%\right.$, Vetec, Rio de Janeiro, Brazil) and ethanol $\left(\mathrm{C}_{2} \mathrm{H}_{5} \mathrm{OH}, \geq 95 \%\right.$, Vetec, Rio de Janeiro, Brazil) were treated with $3 \mathrm{~A}$ molecular sieves (Sigma-Aldrich, Saint Louis, USA) $24 \mathrm{~h}$ before catalytic tests. Pyridine $\left(\mathrm{C}_{5} \mathrm{H}_{5} \mathrm{~N}, \geq 99 \%\right.$, Vetec, Rio de Janeiro, Brazil) was distilled over $\mathrm{CaH}_{2}$ and stored with $3 \mathrm{~A}$ molecular sieves.

\section{Catalysts preparation}

The catalysts were prepared by ion-exchange of $\mathrm{H}_{3} \mathrm{PW}_{12} \mathrm{O}_{40}$ (HPW) protons for $\mathrm{Sn}^{\mathrm{II}}$ cations to form $\mathrm{SnHPW}_{12} \mathrm{O}_{40}$ (SnHPW) adopting two methodologies. The first one was a conventional ion-exchange method in aqueous solution (CS), ${ }^{15}$ where HPW was dissolved in distilled water at room temperature and the required amount of $\mathrm{SnCl}_{2} \cdot 2 \mathrm{H}_{2} \mathrm{O}$ was added under constant stirring (900 rpm). After $3 \mathrm{~h}$, the water was evaporated and the solid obtained was calcined at $200^{\circ} \mathrm{C}$ for 2 (CS2h) or $4 \mathrm{~h}$ (CS4h). The second method was performed in the solid-state (SS), where HPW and the required amount of metallic tin were macerated in a mortar until a homogeneous mixture was obtained. Then, the material was also calcined at $200{ }^{\circ} \mathrm{C}$ for 2 (SS2h) or $4 \mathrm{~h}$ (SS4h).

\section{Catalysts characterization}

The synthesized catalysts, after cooling at ambient conditions, were characterized using the following techniques: Fourier transform infrared spectroscopy (FTIR), X-ray diffraction (XRD), thermal analysis (thermogravimetry/derivative thermogravimetry (TG/ DTG)) and electron dispersive X-ray spectroscopy (EDX).

The infrared spectra of the materials were obtained from a Thermo Scientific spectrophotometer, model Nicolet 6700. The measurements were performed using $\mathrm{KBr}$ tablets at $4 \mathrm{~cm}^{-1}$ resolution and 128 scans.

The diffractograms of the materials were obtained on a Bruker D8 Focus diffractometer with $\mathrm{Cu} \mathrm{K} \alpha$ $(\lambda=1.5418 \AA$ ) , tube power at $40 \mathrm{kV}$ and $30 \mathrm{~mA}$. The $2 \theta$ angle ranged from 5 to $90^{\circ}$ with a sweep speed of $1^{\circ} \mathrm{min}^{-1}$. The unit cell parameter $(a)$ for the cubic lattice was determined using equation 1 :

$a=\mathrm{d}_{h k l}\left(h^{2}+k^{2}+l^{2}\right)^{1 / 2}$

where $\mathrm{d}_{h k l}$ is the interplanar spacing of $h, k, l$ planes.

The TG/DTG curves of the materials were obtained in a 2960 Simultaneous DSC-TGA (TA Instruments) using $\mathrm{N}_{2}(99.999 \%)$ as purge gas $\left(100 \mathrm{~mL} \mathrm{~min}{ }^{-1}\right)$ at a rate of $10{ }^{\circ} \mathrm{C} \mathrm{min}^{-1}$.

The EDX data of the materials were obtained using the EDX 720 equipment (Shimadzu) with a rhodium tube. The samples were analyzed in vacuum at 15 and $50 \mathrm{kV}$. The oxide content was determined by means of comparison with fundamental standards.

In order to evaluate the catalysts acidic sites, a pyridine gas phase adsorption experiment was carried out using the following steps: $(i)$ the samples were loaded in individual aluminum crucibles and placed in a rectangular porcelain plate; (ii) the system was inserted in a glass reactor adapted to a tubular furnace (Model F21135, Thermolyne); (iii) the materials were dehydrated in $\mathrm{N}_{2}$ atmosphere $\left(100 \mathrm{~mL} \mathrm{~min}{ }^{-1}\right.$ ) at $300{ }^{\circ} \mathrm{C}$ for $1 \mathrm{~h}$; (iv) after cooling to $100{ }^{\circ} \mathrm{C}$, gaseous pyridine diluted in $\mathrm{N}_{2}$ was passed through the samples for $1 \mathrm{~h}$; and $(v)$ physically adsorbed pyridine was removed by holding the temperature at $100{ }^{\circ} \mathrm{C}$ under $\mathrm{N}_{2}$ for 2 h. ${ }^{16,17}$ The samples were analyzed by TG/DTG.

\section{Lactic acid esterification reaction}

The catalytic activity of the prepared materials was tested in the reaction of esterification of lactic acid with 

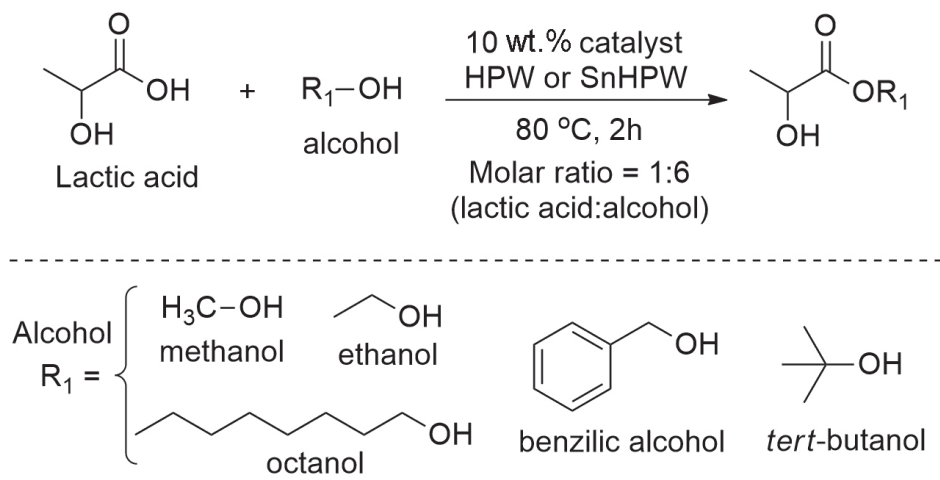

Scheme 3. Lactic acid esterification reaction with different alcohols in the presence of HPW (homogeneous catalysis) and tin-modified catalysts (heterogeneous catalysis).

different alcohols: methanol, ethanol, octanol, tert-butanol and benzyl alcohol (Scheme 3). The reactions were carried out in a closed glass reactor ${ }^{16}$ under constant stirring of $900 \mathrm{rpm}$ and temperature of $80{ }^{\circ} \mathrm{C}$ for $2 \mathrm{~h}$. The amount of catalyst used (dried at $200{ }^{\circ} \mathrm{C}$ for $2 \mathrm{~h}$ ) was $10 \mathrm{wt} . \%$ (or $0.3 \mathrm{~mol} \%$ ) in comparison to the lactic acid. The molar ratios of lactic acid:alcohol used in this work were 1:6 (optimized conditions). The esterification reactions were analyzed by gas chromatography-flame ionization detector (GC-FID; GC-17A from Shimadzu) with an EtileWax ${ }^{\circledR}$ column $(30 \mathrm{~m} \times 0.32 \mathrm{~mm} \times 0.5 \mu \mathrm{m})$.

\section{Results and Discussion}

The conventional ion-exchange method in aqueous solution (CS) was employed using a tin(II) salt and HPW, as elucidated and extensively reported in literature. ${ }^{1,2,15}$ On the other hand, the solid-state method (SS) involved the maceration of HPW and metallic tin, i.e., the steps of reagents dissolution, stirring time, solvent evaporation and use of energy consumption equipment were eliminated. This innovative method was developed by our research group and is aligned with environmentally friendly purposes.

\section{Structural characterization}

In order to characterize the catalyst, it is necessary to evaluate if the insertion of tin(II) caused any change in the HPW structure, i.e., primary (Keggin anion), secondary and tertiary structures. ${ }^{18}$

Solid Keggin-type HPAs are ionic crystals composed by polyanions (primary structure), cations and water. ${ }^{18}$ The $3 \mathrm{D}$ arrangement formed by the latter is known as secondary structure and presents hydrated protons $\left(\left[\mathrm{H}\left(\mathrm{H}_{2} \mathrm{O}\right)_{n}\right]^{+}\right)$, hydrogen bonded to terminal oxygens of neighboring polyanions. ${ }^{18}$ The main bands observed in the IR spectrum of HPW at 1080, 982, 890 and $795 \mathrm{~cm}^{-1}$ are related to the asymmetric stretching of $\mathrm{P}-\mathrm{O}, \mathrm{W}=\mathrm{O}_{\text {terminal }}, \mathrm{W}-\mathrm{O}_{\text {corner }}-\mathrm{W}$ and $\mathrm{W}-\mathrm{O}_{\text {edge }}-\mathrm{W}$ bonds, respectively (Figure 1). ${ }^{15,17}$ These bands were not shifted for SnHPW materials, indicating that the Keggin structure remained unchanged during the two synthetic processes, in accordance with the work developed by Kumar et al. ${ }^{15}$ This result was expected because the ionic radius of $\mathrm{Sn}^{2+}$ ( $\mathrm{r}=1.18 \AA$, hexa-coordinated) is smaller than the hydrated proton $\left(\mathrm{H}_{5} \mathrm{O}_{2}^{+}, \mathrm{r}=2.80 \AA\right)^{19}$ found in the secondary structure of $\mathrm{H}_{3} \mathrm{PW}_{12} \mathrm{O}_{40} \cdot 6 \mathrm{H}_{2} \mathrm{O}$. Shifts on $\mathrm{W}-\mathrm{O}_{\text {edge }}-\mathrm{W}$ and $\mathrm{W}=\mathrm{O}_{\text {terminal }}$ bands can be observed when large cations are used as counterions, resulting in reduced anion-anion interactions. ${ }^{20}$

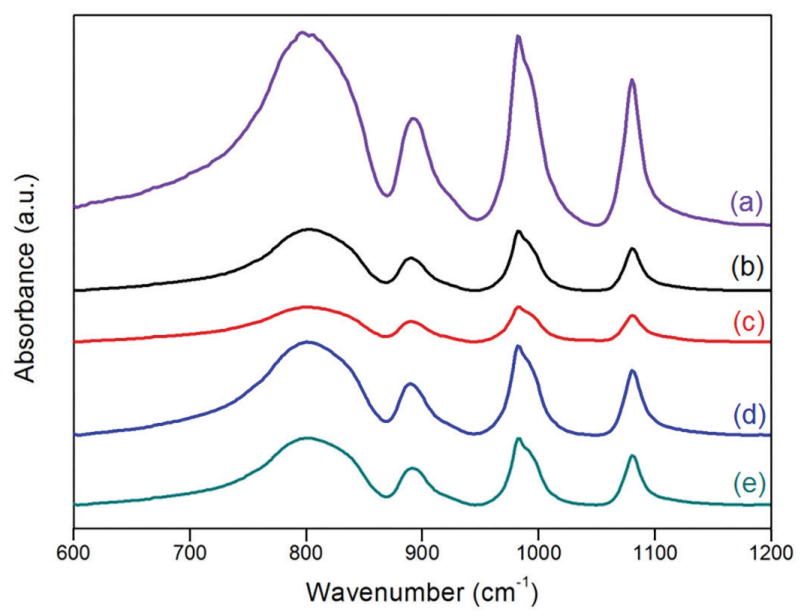

Figure 1. FTIR spectra (KBr) of samples (a) HPW; (b) CS2h; (c) CS4h; (d) SS2h and (e) SS4h.

The secondary structure of HPW and SnHPW materials was investigated using XRD patterns, see Figure 2.

The observed signals at 14.25, 17.50, 20.35, 22.80, $25.05,29.05,30.85,34.30$ and $37.40^{\circ}$ were characteristic of the HPW crystalline cubic structure and were associated with the planes (200), (211), (220), (310), (222), (400), (411), (332) and (510), respectively. ${ }^{21}$ All SnHPW catalysts evidenced the characteristic signals of the HPW cubic lattice, i.e., the secondary structure of HPW was preserved after 


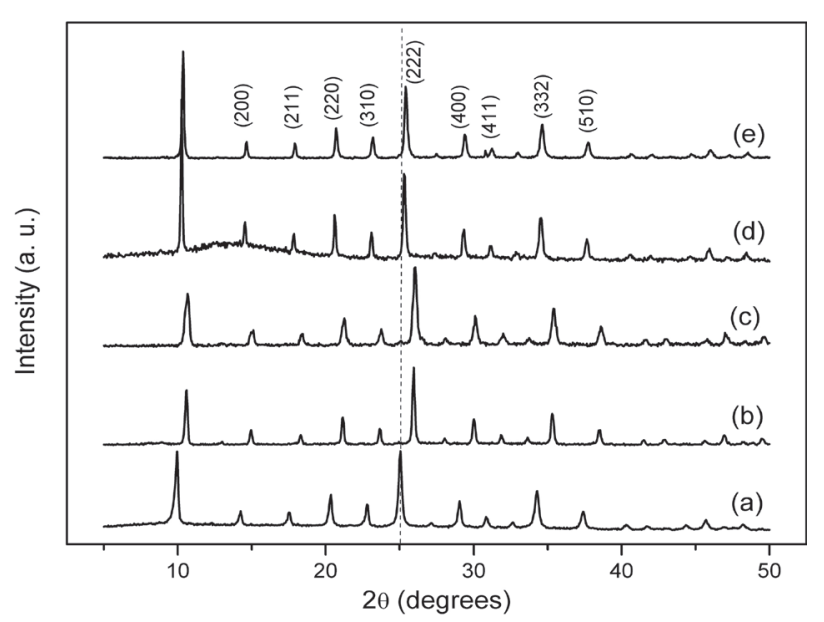

Figure 2. XRD patterns of (a) HPW; (b) CS4h; (c) SS4h; (d) CS2h and (e) SS2h.

the synthetic procedures. However, these materials showed shifts to higher $2 \theta$ values when compared to HPW, implying a contraction of the unit cell. In fact, the determination of the unit cell parameter (a) using the (222) plane and equation 1 showed values of $12.10,12.15,11.87$ and $11.87 \AA$ for SS2h, CS2h, SS4h and CS4h, respectively, in comparison to 12.28 for HPW. This contraction was in accordance with the replacement of $\mathrm{H}_{5} \mathrm{O}_{2}{ }^{+}$for tin(II), a smaller counterion.

HPW tertiary structure is formed by grouping the secondary structures in solid particles. This agglomeration is responsible for generating the material intrinsic properties, such as pore volume, surface area and solubility. ${ }^{22}$ The replacement of protons by different cations can significantly influence the textural properties of HPA compounds. For example, if the ionic radius of the cation is large, $\mathrm{K}^{+}, \mathrm{Rb}^{+}$, $\mathrm{Cs}^{+}$and $\mathrm{NH}_{4}{ }^{+}$, water-insoluble salts are formed, with micro/ mesoporous structures and with a surface area greater than $100 \mathrm{~m}^{2} \mathrm{~g}^{-1}$. Whereas salts formed by small cations are more soluble and have a surface area of less than $10 \mathrm{~m}^{2} \mathrm{~g}^{-1} \cdot{ }^{23} \mathrm{In}$ the case of $\mathrm{Sn}^{2+}$, which presents an ionic radius of $1.18 \AA$, similar to $\mathrm{Ag}^{+}(1.26 \AA),{ }^{24}$ it was not observed a significant increase in the catalyst surface area, but is insoluble in water, the main characteristic of a heterogeneous catalyst.

The analysis of the samples by TG/DTG showed that the structure of the catalysts remained unchanged up to a temperature close to $300{ }^{\circ} \mathrm{C}$, presenting a good thermal stability (graphics from TG/DTG analysis can be seen in Figures S1-S5 in Supplementary Information section). Mass losses observed up to $300{ }^{\circ} \mathrm{C}$ were due to the physically and chemically adsorbed water (equation 2). Above $300{ }^{\circ} \mathrm{C}$ the collapse of the structure begins with the formation of anhydride phase between 432 and $582{ }^{\circ} \mathrm{C}$ (equation 3). ${ }^{23}$ The complete decomposition of the Keggin anions to the respective oxides was observed around $600{ }^{\circ} \mathrm{C}$ (equation 4$)^{25}$

$$
\begin{aligned}
& \mathrm{SnHPW}_{12} \mathrm{O}_{40} \cdot \mathrm{nH}_{2} \mathrm{O}_{(\text {aq) }} \rightarrow \mathrm{SnHPW}_{12} \mathrm{O}_{40(\mathrm{~s})}+\mathrm{nH}_{2} \mathrm{O}_{(\mathrm{g})} \\
& \mathrm{SnHPW}_{12} \mathrm{O}_{40(\mathrm{~s})} \rightarrow \mathrm{SnPW}_{12} \mathrm{O}_{39.5(\mathrm{~s})}+{ }^{1 / 2} \mathrm{H}_{2} \mathrm{O}_{(\mathrm{g})} \\
& \mathrm{SnPW}_{12} \mathrm{O}_{39.5(\mathrm{~s})}+1 / 2 \mathrm{O}_{2(\mathrm{~g})} \rightarrow 1 / 2 \mathrm{P}_{2} \mathrm{O}_{5(\mathrm{~s})}+12 \mathrm{WO}_{3(\mathrm{~s})}+ \\
& \mathrm{SnO}_{2(\mathrm{~s})}
\end{aligned}
$$

The data obtained by EDX and TG/DTG were used to determine the chemical formula of the prepared catalysts. For the EDX analysis, the samples were calcined at $1000^{\circ} \mathrm{C}$ to form the most stable oxides of the elements. Since the evolution of $\mathrm{P}_{2} \mathrm{O}_{5}$ happens around $600{ }^{\circ} \mathrm{C},{ }^{25}$ its values were calculated from the amount of $\mathrm{WO}_{3}$ and $\mathrm{SnO}_{2}$ found with EDX. Table 1 displays the values of the oxides in the prepared catalysts. The desired stoichiometry was to exchange two protons for one tin(II) in both CS method (see equation 5) and SS method (see equation 6). ${ }^{26}$

$$
\begin{aligned}
& \mathrm{SnCl}_{2 \text { (aq) }}+\mathrm{H}_{3} \mathrm{PW}_{12} \mathrm{O}_{40(\mathrm{aq})} \rightleftharpoons \mathrm{SnHPW}_{12} \mathrm{O}_{40(\mathrm{~s})}+2 \mathrm{HCl}_{\text {(aq) }} \\
& \mathrm{Sn}_{(\mathrm{s})}+\mathrm{H}_{3} \mathrm{PW}_{12} \mathrm{O}_{40(\mathrm{~s})} \rightarrow \mathrm{SnHPW}_{12} \mathrm{O}_{40(\mathrm{~s})}+\mathrm{H}_{2(\mathrm{~g})}
\end{aligned}
$$

Table 1. EDX analysis of the synthesized catalysts

\begin{tabular}{lccc}
\hline \multirow{2}{*}{ Oxide } & \multicolumn{2}{c}{ Sample } & Theoretical \\
\cline { 2 - 3 } & CS method & SS method & \\
\hline $\mathrm{WO}_{3} / \%$ & 93.33 & 91.62 & 92.62 \\
$\mathrm{SnO}_{2} / \%$ & 4.29 & 6.04 & 5.02 \\
$\mathrm{P}_{2} \mathrm{O}_{5} / \%$ & 2.38 & 2.34 & 2.36 \\
\hline
\end{tabular}

CS: conventional aqueous ion-exchange; SS: redox solid-state; SnHPW: $\mathrm{SnHPW}_{12} \mathrm{O}_{40}$.

Following the appropriate proportions of the oxides, it was possible to elucidate the chemical formulas of the synthesized catalysts, resulting for the CS method, $\mathrm{Sn}_{0.85} \mathrm{H}_{1.30} \mathrm{PW}_{12} \mathrm{O}_{40}$, and $\mathrm{Sn}_{1.21} \mathrm{H}_{0.58} \mathrm{PW}_{12} \mathrm{O}_{40}$ for the SS method. The values obtained from both ion exchange methods were close to the expected theoretical values. However, to prepare the catalysts using the CS method, tin chloride dihydrate was used and its actual hydration degree was not evaluated. So then, this salt may have a higher hydration degree that was neglected for the preparation of the catalyst, thus, the actual mass of tin(II) may have been less than the calculated. Therefore, the catalysts prepared by CS method showed a lower number of $\mathrm{Sn}^{\text {II }}$ in its structure when compared to the SS method.

The total number of acid sites in the materials was calculated based on the amount of pyridine chemically adsorbed (Table 2). The number of protons in the catalysts structure was calculated according to the chemical formula commented before.

These values showed that the acidity was increased for most of the materials after the insertion of tin(II) when compared to the experimental value of HPW. Moreover, 
Table 2. Total number of acid sites and $\mathrm{H}^{+}$sites

\begin{tabular}{lccc}
\hline Sample & $\begin{array}{c}\text { Total number of } \\
\text { sites } /\left(\mathrm{mmol} \mathrm{g}^{-1}\right)\end{array}$ & $\begin{array}{c}\text { Number of } \mathrm{H}^{+} \\
\text {sites } /\left(\mathrm{mmol} \mathrm{g}^{-1}\right)\end{array}$ & $\begin{array}{c}\text { Number of } \mathrm{Sn}^{2+} \\
\text { sites } /\left(\mathrm{mmol} \mathrm{g}^{-1}\right)\end{array}$ \\
\hline CS2h & 0.94 & 0.44 & 0.50 \\
CS4h & 0.99 & 0.44 & 0.45 \\
SS2h & 1.00 & 0.19 & 0.81 \\
SS4h & 0.97 & 0.19 & 0.78 \\
HPW & 0.96 & 1.04 & - \\
\hline
\end{tabular}

CS2h, CS4h: conventional aqueous ion-exchange calcined at $200{ }^{\circ} \mathrm{C}$ for 2 and $4 \mathrm{~h}$, respectively; SS: redox solid-state calcined at $200^{\circ} \mathrm{C}$ for 2 and 4 h, respectively; $\mathrm{HPW}: \mathrm{H}_{3} \mathrm{PW}_{12} \mathrm{O}_{40}$.

the number of proton sites was much lower than the total number of sites, indicating that the insertion of tin(II) led to the creation of Lewis acid sites. It is possible to observe the relationship between the number of $\mathrm{Sn}^{\mathrm{II}}$ in the catalyst structure and its acidity. The samples that have more tin(II) in their structure, SS2h and SS4h, consequently present a greater number of Lewis acid sites.

\section{Catalytic activity for lactic acid esterification}

The esterification reactions were used to evaluate the catalytic activity and efficiency of the heteropolyacid catalysts prepared. Since esterification reaction is a reversible process, the increase in the reagents proportion shifts the reaction equilibrium to form the products. In order to evaluate the effect of lactic acid to alcohol molar ratio, catalytic tests were performed fixing the following parameters: $80^{\circ} \mathrm{C}, 2 \mathrm{~h}, 10 \mathrm{wt} . \%$ catalyst and ethanol, with SS4h sample as catalyst. Table 3 shows the results obtained with $1: 1 ; 1: 6$ and $1: 10$ acid:ethanol molar ratio.

Table 3. Esterification reactions of lactic acid with ethanol using SS4h as catalyst $\left(80^{\circ} \mathrm{C}, 2 \mathrm{~h}\right.$ and $10 \mathrm{wt} . \%$ catalyst $)$

\begin{tabular}{lc}
\hline Molar ratio (acid:alcohol) & Conversion / \% \\
\hline $1: 1$ & 42.4 \\
$1: 6$ & 72.5 \\
$1: 10$ & 30.1 \\
\hline
\end{tabular}

For the 1:1 ratio, the ester production was not favored by the equilibrium shift because there was no excess of one of the reagents, therefore, the conversion did not exceed 50\%. Also, water can compete in the reverse mechanism leading to hydrolysis of the ester, regenerating lactic acid and ethanol. For the 1:6 ratio there was considerable increase of conversion $(72.5 \%)$, the best result at this condition due to the excess of alcohol. Indeed, several articles in literature ${ }^{27}$ have shown good results with proportions from 1:1 to 1:6, or even higher. However, in this study this phenomenon was observed up to the ratio of 1:6, above this proportion there was a decrease in conversion, as can be seen in Table 3 . The excess of alcohol in the 1:10 ratio could be associated to catalyst acid sites saturation. Based on the above results, all catalytic tests were conducted at 1:6 molar ratio with several alcohols (methanol, ethanol and octanol). The results are shown in Table 4.

Table 4. Esterification reactions of lactic acid 1:6 (acid:alcohol) at $80^{\circ} \mathrm{C}$ during $2 \mathrm{~h}$

\begin{tabular}{lccc}
\hline Catalyst & Alcohol & Conversion / \% & $\begin{array}{c}\mathrm{TON}^{\mathrm{a}} / \\
\left(\mathrm{mol}_{\text {ester }} \mathrm{mol}_{\mathrm{cat}}{ }^{-1}\right)\end{array}$ \\
\hline \multirow{3}{*}{ CS2h } & methanol & 90.7 & 107.1 \\
& ethanol & 70.7 & 83.5 \\
\hline \multirow{3}{*}{ CS4h } & octanol & 84.7 & 100.0 \\
\hline \multirow{3}{*}{ SS2h } & methanol & 79.1 & 88.7 \\
& ethanol & 79.4 & 89.0 \\
& octanol & 95.6 & 107.2 \\
\hline \multirow{3}{*}{ SS4h } & methanol & 84.4 & 93.7 \\
& ethanol & 54.0 & 59.9 \\
& octanol & 94.4 & 104.8 \\
\hline \multirow{3}{*}{ HPW } & methanol & 83.6 & 95.7 \\
& ethanol & 72.5 & 83.0 \\
& octanol & 95.9 & 109.8 \\
\hline
\end{tabular}

aTON: turnover number, mol of ester per mol of acid sites, considering the total number of acid sites from Table 2. CS2h, CS4h: conventional aqueous ion-exchange calcined at $200{ }^{\circ} \mathrm{C}$ for 2 and $4 \mathrm{~h}$, respectively; SS: redox solid-state calcined at $200{ }^{\circ} \mathrm{C}$ for 2 and $4 \mathrm{~h}$, respectively; HPW: $\mathrm{H}_{3} \mathrm{PW}_{12} \mathrm{O}_{40}$.

In all cases, the selectivity of the ester was $100 \%$. The blank reaction, which corresponds to the reaction at $80^{\circ} \mathrm{C}$ during $2 \mathrm{~h}$ without catalyst, showed values of 17 , 7 and $12 \%$ conversion to methanol, ethanol and octanol, respectively, demonstrating the effectiveness of the synthesized catalysts.

The esterification reactions were also carried out using HPW under the same reaction conditions in order to compare the conversion of homogeneous HPW with the heterogeneous catalysis obtained with tin(II). According to Table 4, both homogeneous HPW and heterogeneous catalysts (CS2h, CS4h, SS2h and SS4h) showed conversions that ranged from good to excellent (76.0-95.9\%) in the esterification reactions of lactic acid with methanol and octanol. On the other hand, conversions obtained using ethanol were moderate to good (54.0- 
79.4\%). The conversion results obtained with octanol were higher for all catalysts because both alcohol and corresponding ester were insoluble in the lactic acid waterbased solution used as reagent. For that reason, the products (ester and water) were in different phases, thus shifting the reaction equilibrium.

Catalytic activity calculations (turnover frequency, TON, mol of ester per mol of acid sites) showed that the heterogeneous catalyst prepared in the solid-state (104.8 and $109.8 \mathrm{~mol}_{\text {ester }}$ mol $_{\text {cat }}{ }^{-1}$ for SS2h and SS4h, respectively) showed slightly superior catalytic capacity when compared to the classic method (100.0 and $107.2 \mathrm{~mol}_{\text {ester }} \mathrm{mol}_{\text {cat }}{ }^{-1}$ for CS2h and CS4h, respectively), see Table 4, showing that the catalyst prepared by the SS method can replace the CS one and its synthetic pathway is closer to green chemistry. Both catalysts, SS2h and SS4h, showed conversion values above $90 \%$ in reactions with octanol. However, it is noteworthy that the conversion data obtained with the other alcohols were also high when compared with the literature. Sanz et al. ${ }^{28}$ performed the esterification of lactic acid with methanol using different ion exchange resins as catalyst and the data reported did not exceed $45 \%$ conversion. Engin et al. ${ }^{29}$ applied heteropolyacid catalysts, $\mathrm{H}_{3} \mathrm{PW}_{12} \mathrm{O}_{40}$ and $\mathrm{H}_{3} \mathrm{PMo}_{12} \mathrm{O}_{40}$ supported on ion exchange resins in the production of esters from lactic acid and also obtained results that did not exceed $45 \%$. Although HPW presented a TON high value $\left(109.9 \mathrm{~mol}_{\text {ester }} \mathrm{mol}_{\text {cat }}{ }^{-1}\right)$, it has a homogeneous behavior.

Considering the conversion data presented in Table 4, the catalysts CS4h and SS4h, with better average results, were chosen for tests with benzyl and tert-butyl alcohols in the lactic acid esterification reaction (Table 5). These tests were conducted to evaluate alcohol carbonic chain influence on the conversion to esters.

The conversion in the reaction using the tert-butanol alcohol with the heterogeneous catalyst was moderated (40.9-42.0\%) due to the steric impediment of the alcoholic
Table 5. Esterification reactions with benzyl and tert-butyl alcohols $\left(80^{\circ} \mathrm{C}, 2 \mathrm{~h}, 10 \mathrm{wt} . \%\right.$ catalyst and 1:6 molar ratio acid:alcohol)

\begin{tabular}{lccc}
\hline Catalyst & Alcohol & Conversion / \% & $\begin{array}{c}\mathrm{TON}^{\mathrm{a}} / \\
\left(\mathrm{mol}_{\text {ester }} \mathrm{mol}_{\text {cat }}{ }^{-1}\right)\end{array}$ \\
\hline CS4h & benzylalcohol & 83.9 & 94.1 \\
& tert-butanol & 40.9 & 45.9 \\
\hline \multirow{2}{*}{ SS4h } & benzylalcohol & 82.2 & 94.1 \\
& tert-butanol & 42.0 & 48.1 \\
\hline \multirow{2}{*}{ HPW } & benzylalcohol & 77.7 & 89.9 \\
& tert-butanol & 65.8 & 76.1 \\
\hline
\end{tabular}

${ }^{a} \mathrm{TON}$ : turnover number, mol of ester per mol of acid sites, considering the total number of acid sites from Table 2. CS4h: conventional aqueous ion-exchange calcined at $200{ }^{\circ} \mathrm{C}$ for $4 \mathrm{~h}$; SS: redox solid-state calcined at $200{ }^{\circ} \mathrm{C}$ for $4 \mathrm{~h}$; $\mathrm{HPW}: \mathrm{H}_{3} \mathrm{PW}_{12} \mathrm{O}_{40}$.

bulky branched chain, which makes it difficult to carry this alcohol to the acid catalyst sites, where the reaction start with the transformation of tert-butyl alcohol into the tert-butyl carbocation (Scheme 4, step (a)), following the esterification of lactic acid through a nucleophilic attack by a possible $S_{\mathrm{N}} 1$ type mechanism (Table 5 and Scheme 4). Otherwise, the reaction using HPW, homogeneous catalysis, showed higher conversion value $(65.8 \%)$, because it is the hydrogen from the HPW deprotonation that initiates the reaction, with no need for adsorption in the catalyst. The conversion obtained with benzyl alcohol was higher (82.2-83.9\%) which can indicate that the aromatic part (electron rich donor) present in it contribute with the nucleophilic character, therefore, increasing reactivity. The results produced from the esterification reaction with benzyl alcohol were like the conversions obtained with octanol, for the same reasons discussed before about equilibrium shift through product solubility. In both cases, the esterification reactions of lactic acid with benzyl alcohol and octanol pass through mechanisms where the hydroxyl function of the alcoholic component attacks the electrophilic site

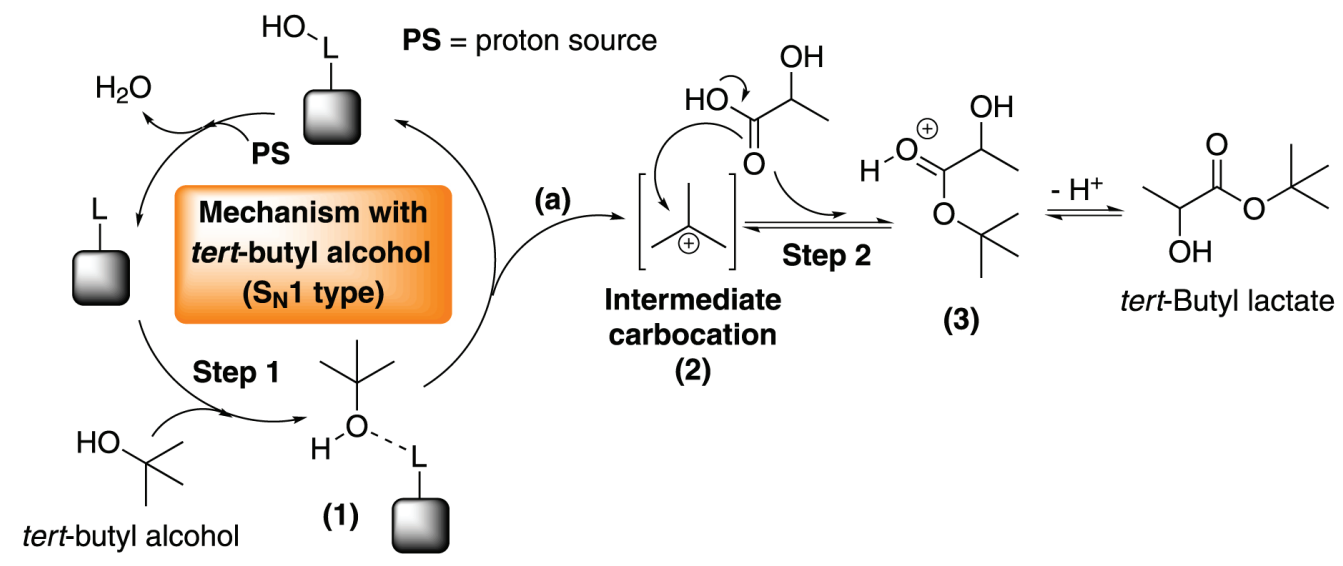

Scheme 4. A possible $\mathrm{S}_{\mathrm{N}} 1$ type esterification mechanism using heterogeneous catalysis and tert-butyl alcohol. L represents Lewis acid site. 
of lactic acid adsorbed on the catalyst, followed by the elimination of water, a different mechanism when using tert-butyl alcohol $\left(\mathrm{S}_{\mathrm{N}} 1\right.$ mechanism). For comparison of the both possible mechanisms proposed, see Schemes 4 and 5.

The mechanism of the esterification reaction, as well as the adsorption and desorption mechanisms of heterogeneous catalysts, showed a greater influence on the result of the conversion of the reactions when compared to the number of acid sites. Scheme 5 shows a mechanistic proposal for the esterification reaction of lactic acid with different unbranched alcohols in the presence of the modified heteropolyacid compounds synthesized. Initially, the mechanism consists in the adsorption/complexation of lactic acid on the surface of the catalyst (structure 1), due to the acid-base interaction between the electron pair of oxygen in the lactic acid carboxyl and the metal present in the catalyst structure (step 1). As a result, there is an increase in polarization and positive charge density in the<smiles>[R]O[C-]([R])O[Tl]C1CCCC1</smiles><smiles>[R]OC([R])=[Te][Te]</smiles>

(9)<smiles>CC(O)C1(C)OCCO1</smiles><smiles>[R]OC([R])(O)O[Tl]C1CCCC1</smiles>

(8)

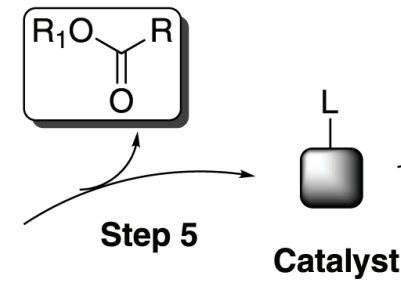

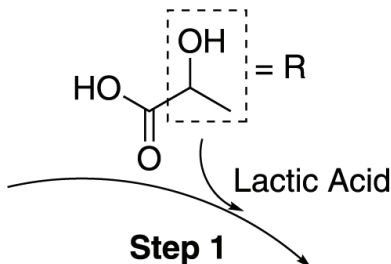<smiles>CC(O)C(O)=C([O-])I(O)C1CCCC1</smiles>

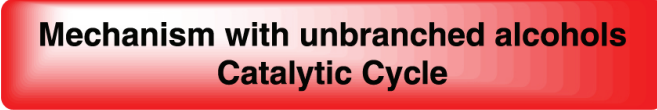
Catalytic Cycle<smiles>[R9]C(C)C(C)C</smiles>

$H B$ Interaction and Proton Transfer Step
HB Interaction and Proton Transfer Step

(6)

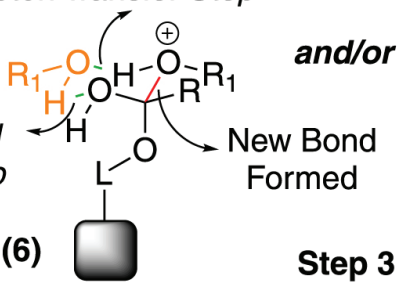

HO<smiles>[R]OC(O)(O)O[Tl]C1[CH]CCC1</smiles>

Two Possible Transitions States (TS*) in the Nucleophilic Addition Step

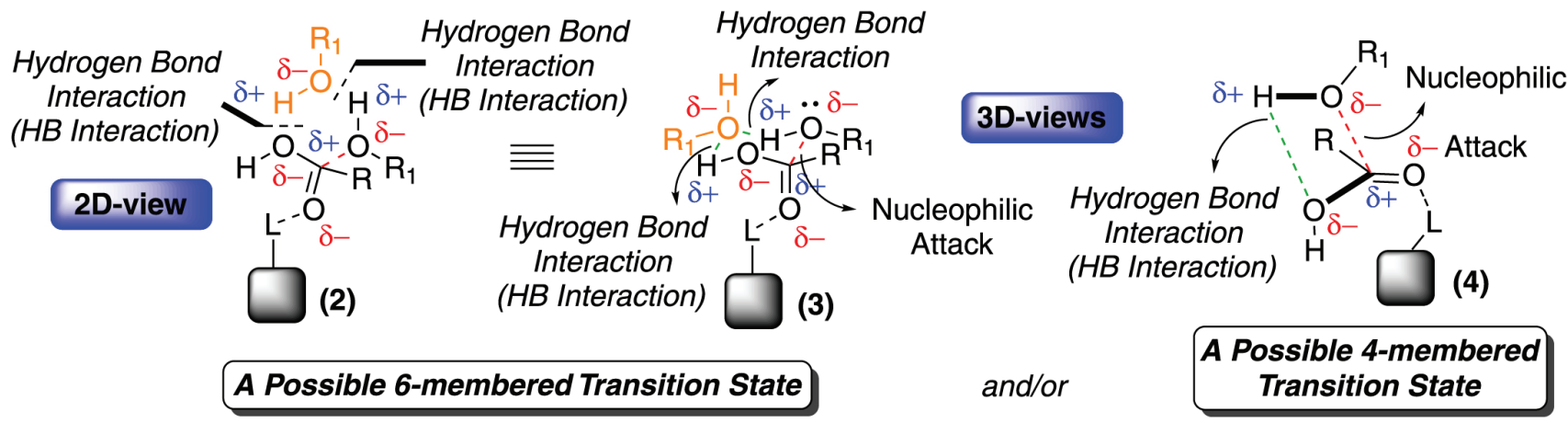

Scheme 5. Esterification mechanism using heterogeneous catalysis and unbranched alcohols. L represents Lewis acid site, R the radical of lactic acid, and $\mathrm{R}_{1}$ the carbon chain of alcohol. Sub-step (a) represents resonance structures between the intermediates (8-9). 
electrophilic site of the carboxylic group (structure 1), supporting the nucleophilic attack of the electron pair of the hydroxyl function of the alcoholic compound with the consequent formation of a tetracoordinate intermediate (5 and/or 6) (step 2). These structures (5) and (6) are formed from two possible transition states (TS*). For the formation of structure (6), probably two alcohol molecules participate in a 6-membered transition state (3) through interactions of hydrogen bonds (HB interactions, showed in green), possibly more arranged and stable, assisting the nucleophilic attack of the alcohol molecule (showed in black) to the electrophilic site of the coordinated carboxyl group with the catalyst. However, for the formation of the structure (5), only one alcohol molecule is used, leading to a less stable 4-membered TS due to the high angular tension adopted in this TS. Then, a proton transfer occurs, leading to the formation of the intermediary (7), in equilibrium stage (step 3), with subsequent elimination of a water molecule (step 4) from the displacement of the oxygen electron pair of the ether function present in the intermediary (5). The proton transfer in step 3 , from structure (6), is assisted by the second alcohol molecule (showed in orange) through interactions of hydrogen bonds. The intermediary structure (8) formed from the resonance between the structures (8) and (9) in step (a) of the proposed mechanism, undergoes desorption/decompression of the corresponding ester formed (step 5), leaving the surface of the free catalyst to participate in the next catalytic cycles. All the steps are in equilibrium and it is necessary to remove the water molecules and/or the product formed so that the balance is favorable in the direction and formation of the desired ester product.

The SS method is a new synthetic procedure to prepare catalytic materials by an innovative green process and has presented satisfactory results by eliminating unitary operations and reagents. In addition, the methodology adopted does not generate chemical residues, since molecular hydrogen can be used as an energy source. The proposed technology can be classified by the technology readiness level (TRL) between 4 and $5,{ }^{30}$ presenting potential for industrial application, since the equipment and materials proposed for its execution are already used in large industries.

\section{Conclusions}

The characterization of the catalysts synthesized by the two methods, CS and SS, showed that the interaction between HPW and tin(II) did not result in considerable changes in HPW primary and secondary structures. The new developed method (SS) is a promising alternative to material syntheses, aligned to green chemistry principles by decreasing residues production, which is extremely relevant and of great interest to chemical industries.

The heteropolyacid modification carried out in this work showed that the prepared materials demonstrated efficiency as heterogeneous catalysts in the lactic acid esterification reaction. In addition, the results obtained by the SS method were superior to those reported in literature. It was demonstrated the great potential of this catalyst for industrial application, both for the environmental and economic aspects, making the whole preparation process less costly.

\section{Supplementary Information}

Supplementary information (TG/DTG curves of SnHPW catalysts) is available free of charge at http://jbcs.sbq.org.br as PDF file.

\section{Acknowledgments}

This study was financed by the Coordination of Superior Level Staff Improvement, Brazil (CAPES), finance code 001, through the master scholarship granted to Ms Mariane Henz. The authors would also like to thank the support of National Council for Scientific and Technological Development (CNPq), Federal District Research Support Foundation (FAPDF) and the Institute of Chemistry of the University of Brasília (IQ/UnB).

\section{Author Contributions}

Mariane M. Henz was responsible for the data curation, investigation, software, validation and writing original draft; Munique G. Guimarães for the data curation, software, validation and writing original draft; Rafael B. W. Evaristo for the data curation, software and writing original draft; Rafael O. Rocha for the investigation, software, validation, writing original draft, review and editing; Lennine R. de Melo for the software, validation, writing original draft, review and editing; Julio L. de Macedo for the conceptualization, formal analysis funding acquisition, investigation, project administration, validation, writing original draft, review and editing; Grace F. Ghesti for the conceptualization, formal analysis funding acquisition, investigation, project administration, validation, writing original draft, review and editing.

\section{References}

1. Southward, B. W. L.; Vaughan, J. S.; Oconnor, C. T.; J. Catal. 1995, 153, 293. 
2. Essayem, N.; Coudurier, G.; Fournier, M.; Vedrine, J. C.; Catal. Lett. 1995, 34, 223.

3. Kozhevnikov, I.; J. Mol. Catal. A: Chem. 2007, 262, 86.

4. Datta, R.; Tsai, S. P.; Bonsignore, P.; Moon, S. H.; Frank, J. R.; FEMS Microbiol. Rev. 1995, 16, 221.

5. Sheldon, R. A.; Catal. Today 2011, 167, 3.

6. Pereira, C. S. M.; Silva, V. M. T. M.; Rodrigues, A. E.; Green Chem. 2011, 13, 2658.

7. Nijenhuis, A. J.; Grijpma, D. W.; Pennings, A. J.; Macromolecules 1992, 25, 6419.

8. Dusselier, M.; Wouwe, P. V.; Dewaele, A.; Makshina, E.; Sels, B. F.; Energy Environ. Sci. 2013, 6, 1415.

9. Vijayakumar, J.; Aravindan, R.; Viruthagiri, T.; Chem. Biochem. Eng. Q. 2008, 22, 255.

10. Mehta, R.; Kumar, V.; Bhunia, H.; Upadhyay, S. N.; J. Macromol. Sci. C 2005, 45, 325.

11. Montelongo, J. L.; Chassy, B. M.; McCord, J. D.; J. Food. Sci. 1993, $58,863$.

12. Hamryszak, L.; Grzesik, M.; Int. J. Chem. Kinet. 2019, 51, 689.

13. Akyalçin, S.; Altiokka, M. R.; Appl. Catal., A 2012, 429-430, 79.

14. Knothe, G.; Energy Environ. Sci. 2009, 2, 759.

15. Kumar, C. R.; Rao, K. T. V.; Prasad, P. S. S.; Lingaiah, N.; J. Mol. Catal. A: Chem. 2011, 337, 17.

16. Borges, L. D.; Moura, N. N.; Costa, A. A.; Braga, P. R. S.; Dias, J. A.; Dias, S. C. L.; Macedo, J. L.; Ghesti, G. F.; Appl. Catal., A 2013, 450, 114.
17. de Mattos, F. C. G.; de Carvalho, E. N. C. B.; de Freitas, E. F.; Paiva, M. F.; Ghesti, G. F.; de Macedo, J. L.; Dias, S. C. L.; Dias, J. A.; J. Braz. Chem. Soc. 2017, 28, 336.

18. Misono, M.; Chem. Commun. 2001, 13, 1141.

19. Volkov, A. G.; Paula, S.; Deamer, D. W.; Bioelectrochem. Bioenerg. 1997, 42, 153.

20. Rocchiccioli-Deltcheff, C.; Fournier, M.; Franck, R.; Thouvenot, R.; Inorg. Chem. 1983, 22, 207.

21. Kremenović, A.; Spasojević-de Biré, A.; Dimitrijević, R.; Sciau, P.; Mioč, U. B.; Colomban, Ph.; Solid State Ionics 2000, 13, 239.

22. Kamiya, Y.; Okuhara, T.; Misono, M.; Miyaji, A.; Tsuji, K.; Nakajo, T.; Catal. Surv. Asia 2008, 12, 101.

23. Haber, J.; Matachowski, L.; Mucha, D.; Stoch, J.; Sarv, P.; Inorg. Chem. 2005, 44, 6695.

24. Kozhevnikov, I. V.; Chem. Rev. 1998, 98, 171.

25. Lide, D. R.; CRC Handbook of Chemistry and Physics, $89^{\text {th }}$ ed.; CRC Press: Boca Raton, USA, 2008.

26. Marme, F.; Coudurier, G.; Védrine, J. C.; Microporous Mesoporous Mater. 1998, 22, 151.

27. Ghesti, G. F.; Macedo, J. L.; Parente, V. C. I.; Dias, J. A.; Dias, S. C. L.; Appl. Catal., A 2009, 355, 139.

28. Sanz, M. T.; Murga, R.; Beltran, S.; Cabezas, J. L.; Ind. Eng. Chem. Res. 2002, 41, 512.

29. Engin, A.; Haluk, H.; Gurkan, K.; Green Chem. 2003, 5, 460.

30. Quintella, C. M.; Cad. Prosp. 2017, 10, 1.

Submitted: May 5, 2020

Published online: October 14, 2020 